\title{
Effects of Phenolic Pollution on Interspecific Competition between Microcystis aeruginosa and Chlorella pyrenoidosa and their Photosynthetic Responses
}

\author{
Xiao Tan ${ }^{1, *}$, Kaiwen Dai ${ }^{1}$, Keshab Parajuli ${ }^{2}$, Xiaoshuai Hang ${ }^{3}$, Zhipeng Duan ${ }^{1}$ and Yue Hu ${ }^{1}$ \\ 1 Key Laboratory of Integrated Regulation and Resource Development on Shallow Lakes, Ministry of \\ Education, College of Environment, Hohai University, Nanjing 210098, China; algaegroup@163.com (K.D.); \\ duanzhipeng@hhu.edu.cn (Z.D.); 1714060112@hhu.edu.cn (Y.H.) \\ 2 School of Population and Global Health, Faculty of Medicine, Denistry and Health Sciences, The University \\ of Melbourne, VIC 3010 Melbourne, Australia; kparajuli@student.unimelb.edu.au \\ 3 Nanjing Institute of Environmental Sciences, Ministry of Ecology and Environment, Nanjing 210042, China; \\ hxs@nies.org \\ * Correspondence: tanxiao@hhu.edu.cn; Tel.: +86-133-7609-4082
}

Received: 13 August 2019; Accepted: 30 September 2019; Published: 17 October 2019

\begin{abstract}
The demand for phenolic compounds has been increasing rapidly, which has intensified the production and usage of phenol at a commercial scale. In some polluted water bodies, phenol has become one of the typical aromatic contaminants. Such water bodies are inescapably influenced by nutrients from human activities, and also suffer from nuisance cyanobacterial blooms. While phenolic pollution threatens water safety and ecological balance, algal cells are ubiquitous and sensitive to pollutants. Therefore, effects of phenolic pollution on interspecific competition between a bloom-forming cyanobacterium and other common alga merit quantitative investigation. In this study, the effects of phenol on Microcystis aeruginosa (M. aeruginosa, a bloom-forming cyanobacterium) and Chlorella pyrenoidosa (C. pyrenoidosa, a ubiquitous green alga) were analyzed in mono- and co-cultures. The two species were exposed to a series of phenol treatments $\left(0,2,20\right.$, and $\left.200 \mu \mathrm{gL}^{-1}\right)$. Population dynamics were measured by a flow cytometer and analyzed by the Lotka-Volterra model. The results showed that $M$. aeruginosa was more sensitive to phenol $\left(\mathrm{EC}_{50}=80.8 \pm 0.16 \mu \mathrm{gL}^{-1}\right)$ compared to C. pyrenoidosa $\left(\mathrm{EC}_{50}=631.4 \pm 0.41 \mu \mathrm{g} \mathrm{mL} \mathrm{m}^{-1}\right)$ in mono-cultures. M. aeruginosa won in the co-cultures when phenol was below or equal to $20 \mu \mathrm{g} \mathrm{mL}^{-1}$, while C. pyrenoidosa became the dominant species in the $200 \mu \mathrm{g} \mathrm{mL}^{-1}$ treatment. Photosynthetic activity was measured by a fluometer. Results showed phenol significantly impacted the photosynthetic activity of $M$. aeruginosa by inhibiting the acceptor side of its photosystem II (PSII), while such inhibition in C. pyrenoidosa was only observed in the highest phenol treatment $\left(200 \mu \mathrm{g} \mathrm{mL}^{-1}\right)$. This study provides a better understanding for predicting the succession of algal community structure in water bodies susceptible to phenolic contamination. Moreover, it reveals the mechanism on photosynthetic responses of these two species under phenolic stress.
\end{abstract}

Keywords: phenol; cyanobacteria; green algae; interspecific competition; Lotka-Volterra model; dominance establishment; photosynthetic activity

Highlights: M. aeruginosa was dominant in co-cultures with C. pyrenoidosa at a lower concentration of phenol (below or equal to $20 \mu \mathrm{g} \mathrm{mL}^{-1}$ ). A higher concentration of phenolic pollution (up to $200 \mu \mathrm{g} \mathrm{mL}^{-1}$ ) facilitated the dominance of $C$. pyrenoidosa in co-cultures with $M$. aeruginosa. Phenol inhibits the acceptor side of electron transport chain and reduces the number of active reaction centers of photosystem II in M. aeruginosa cells. 


\section{Introduction}

Phenol is a common aromatic organic compound in surface waters [1-3], and mainly originates with wastewaters from various industries, including the coal mining, phenol production, and textile industries [4,5]. In China, phenol is generally at 0.2 to $12 \mu \mathrm{g} \mathrm{L}^{-1}$ in unpolluted lakes [6,7]. However, its concentration can be much higher in wastewater from petroleum refineries $\left(13-88 \mu \mathrm{g} \mathrm{mL}^{-1}\right)$ and in coke wastewater $\left(180 \mu \mathrm{g} \mathrm{mL}^{-1}\right)$ from steel facilities [3]. In 2005, in Tonglu County (China), the concentration of phenol reached $243 \mu \mathrm{g} \mathrm{mL}^{-1}$ in the polluted water area [8]. More recently, with the increasing production and usage of phenol, large numbers of lakes and rivers suffer from phenolic pollution.

The presence of phenol in water bodies generally poses severe risks to human health (corrosive and carcinogenic toxicity) and water safety. Moreover, phenolic pollution can threaten the balance of aquatic ecosystems. Algal cells are ubiquitous, and are sensitive to aromatic pollutants. Therefore, greater insights into their damaging effects on phytoplankton are crucial, given their role on primary productivity in ecosystems. Several studies have reported that the structure of algal cells can be affected by the existence of phenol; for instance, the membranes of algal cells may be damaged by hydrophobic interaction with lipid bilayer structures [9,10]. Additionally, photosynthetic systems of algal cells might be damaged by phenol, as recent studies have shown that phenol changes their PSII structures and functions $[10,11]$. However, most studies have focused on the effects of phenol on the growth and physiology of single algal species in mono-cultures [11-13], while there is a lack of information on its influence on interspecific competition and dominance establishment. Such knowledge is of critical significance in relation to predicting and protecting the stability of aquatic ecosystems.

In recent years, some studies have shown that organic pollutants (such as alkylbenzene sulfonate and pentachlorophenol) have the potential to overturn algal community structure [14,15]. For example, M. aeruginosa competed over Scenedesmus obliquus in co-cultures without alkylbenzene sulfonate (LAS), while the result was opposite when LAS $\left(20 \mu \mathrm{g} \mathrm{mL}{ }^{-1}\right)$ was added in co-cultures [15]. Similarly, the effects of pentachlorophenol (PCP) on M. aeruginosa and Chlorella vulgaris were studied in co-cultures [16]. Results showed that the effect of PCP on M. aeruginosa was concentration-specific, where low levels of PCP promoted the growth of $M$. aeruginosa, while high concentrations of PCP significantly inhibited its growth. However, no toxic effect of PCP on C. vulgaris was observed. This suggests that exogenous pollutants can affect the interspecific competition between M. aeruginosa and S. obliquus, thereby influencing the community structure. Moreover, it has been reported that polycyclic aromatic hydrocarbons (PAHs) could also affect the algal interspecific competition [14,17]. Despite the potential influences of organic pollutants on the interspecific relationships, the mechanism involved in the competitive process still remain open for further investigation, which merits quantitative analysis to better understand such phenomena under polluted conditions.

Cyanobacterial blooms threaten drinking water supplies, fisheries, and recreational activities. Competition between cyanobacteria and green algae affects phytoplankton succession and the formation of blooms [18]. In China, Microcystis is a very common bloom-forming cyanobacterium. Some organic compounds could influence the growth of Microcystis [15,19], while the detailed information about the competition between Microcystis and other algae under the stress of phenol is still unclear. Therefore, in this study, two common species of phytoplankton (M. aeruginosa and C. pyrenoidosa) were chosen to investigate the effects of phenol in mono- and co-cultures. Their growth and photosynthetic parameters were measured to analyze their competitive relationships and photosynthetic responses to various concentrations of phenol. We aimed to provide some useful information for predicting the succession of algal community structure in water bodies susceptible to phenolic contamination. 


\section{Materials and Methods}

\subsection{Preparation of Chemical Reagents}

Phenol was purchased from Aladdin Industrial Corporation of Shanghai, with a purity $>99.0 \%$, which was pre-dissolved in dimethyl sulfoxide (DMSO). The concentration of DMSO was lower than $0.5 \mathrm{~mL} \mathrm{~L}^{-1}$ to ensure DMSO was nontoxic to algal cells [20]. The phenol-DMSO solution was stored in an airtight bottle and was protected from light.

\subsection{Strains and Culture Conditions}

M. aeruginosa (PCC-7806) and C. pyrenoidosa (FACHB-11) were purchased from the Institute of Hydrobiology, Chinese Academy of Science. The two strains were cultured in sterilized BG11 media [21] at $25 \pm 0.5^{\circ} \mathrm{C}$, with a light: dark cycle of $12 \mathrm{~h}: 12 \mathrm{~h}$ at $65 \mu \mathrm{mol}$ photons $\mathrm{m}^{-2} \mathrm{~s}^{-1}$ (FSL, China). Algal cells in the mid-exponential growth phase were used for the experiments.

\subsection{Experimental Design}

To evaluate the effects of phenol on growth, photosynthesis, and interspecific competition between M. aeruginosa and C. pyrenoidosa, their mono-cultures and co-cultures were designed. Experiments were carried out in $250 \mathrm{~mL}$ Erlenmeyer flasks containing $100 \mathrm{~mL}$ algal suspension. Phenol was set at four treatment groups $\left(0,2,20\right.$, and $\left.200 \mu \mathrm{g} \mathrm{mL} \mathrm{m}^{-1}\right)$, to reflect its concentrations in polluted water bodies in China mentioned above. In this study, the initial biomass ratio of M. aeruginosa to C. pyrenoidosa was set at 1:1, and the initial cell concentration was adjusted based on the volume of individual cells [22]. Therefore, the cell concentrations of $M$. aeruginosa and C. pyrenoidosa were set at $1.0 \times 10^{5}$ and $2.0 \times 10^{5}$ cells $\mathrm{mL}^{-1}$ at the beginning, respectively. Experiments were carried out in triplicate.

\subsection{Cell Counting}

Cells of the two species are similar in size and morphology, which are difficult to be distinguished and enumerated accurately by an optical microscope. Therefore, flow cytometry (Accuri C6 plus, BD) was employed to analyze cell concentrations every two days. Replicated samples (2 mL) from the different treatment groups were analyzed. For the quantification of cell concentration, an aliquot of a calibrated solution of fluorescent beads ( $1 \mu \mathrm{m}$ diameter, BD) was added in each sample as an internal standard. Two species were differentiated by auto-fluorescent signals of chlorophyll and phycocyanin.

\subsection{Measurement of In Vivo Chlorophyll-a Fluorescence}

To monitor photosynthetic activity responses to phenol, photosynthetic efficiencies of monocultured M. aeruginosa and C. pyrenoidosa were determined by in vivo chlorophyll-a (Chl $a)$ fluorescence. Firstly, $2 \mathrm{~mL}$ of algal cells were kept in the dark for $15 \mathrm{~min}$. Then a series of chlorophyll-a fluorescence parameters and the induction curves were recorded by a FluorPen fluorometer (AquaPen C100, Photon Systems Instruments, Czech) at room temperature [23-25]. This fluorometer was equipped with two types of excitation wavelength at $455 \mathrm{~nm}$ and $620 \mathrm{~nm}$. The OJIP test (Fluorescence response curves detection) was conducted to analyze the changes in these fluorescent parameters, which can provide adequate information about the structure, conformation, and the function of photosynthetic apparatus. From the OJIP transient, the measured parameters $\left(F_{0}, F_{m}, F_{300 \mu s}, F_{J}, F_{I}\right.$ and so on) were used to calculate new parameters, which are displayed in Table 1 [24,25]. 
Table 1. Formulae or terms of the OJIP transient [24,25].

\begin{tabular}{|c|c|}
\hline Formulae or terms & Description \\
\hline$F_{0}$ & Minimum fluorescence \\
\hline$F_{m}$ & Maximum fluorescence \\
\hline$V_{J}=\left(F_{2 m s}-F_{0}\right) /\left(F_{m}-F_{0}\right)$ & Relative variable fluorescence at $2 \mathrm{~ms}$ \\
\hline$M_{0}=4\left(F_{300 \mu s}-F_{0}\right) /\left(F_{m}-F_{0}\right)$ & $\begin{array}{c}\text { Approximated initial slope (in } \mathrm{ms}^{-1} \text { ) of the fluorescence transient } V=f \\
(t) ; \text { It is a measure of the rate of the primary photochemistry }\end{array}$ \\
\hline$V_{K}=\left(F_{300 \mu s}-F_{0}\right) /\left(F_{m}-F_{0}\right)$ & Relative variable fluorescence at $300 \mu \mathrm{s}$ \\
\hline$F_{v} / F_{m}$ & The maximum quantum yield of primary photochemistry at $t=0$ \\
\hline$E T_{0} / T R_{0}=1-V_{J}$ & $\begin{array}{c}\text { Probability (at time } 0) \text { that a trapped exciton moves an electron into the } \\
\text { electron transport chain beyond } \mathrm{Q}_{\mathrm{A}}^{-}\end{array}$ \\
\hline$E T_{0} / \mathrm{RC}=\left(M_{0} / V_{J}\right) \times\left(1-V_{J}\right)$ & Electron transport from $\mathrm{Q}_{\mathrm{A}}$ to $\mathrm{Q}_{\mathrm{B}}$ flux per $\mathrm{RC}$ (reaction center) \\
\hline$A B S / R C=\left[M_{0}\left(1 / V_{J}\right) /\left(F_{v} / F_{m}\right)\right]$ & Absorption flux per RC \\
\hline$F_{v} / F_{0}$ & An indicator of the efficiency in the primary photochemical reaction \\
\hline $\begin{array}{l}\text { Fraction of } \mathrm{OEC}=\left[1-\left(V_{K} / V_{J}\right)\right]_{\text {treated }} /[1- \\
\left.\qquad\left(V_{K} / V_{J}\right)\right]_{\text {control }}\end{array}$ & $\begin{array}{l}\text { The fraction of OEC (oxygen-evolving complex) in comparison with the } \\
\text { control }\end{array}$ \\
\hline$D I_{0} / R C=A B S / R C-T R_{0} / R C$ & Dissipated energy flux per RC at $t=0$ \\
\hline
\end{tabular}

\subsection{Measurement of Dissolved Phenol Concentration}

The concentration of dissolved phenol was determined every two days after filtration (using GF/F membrane, Whatman) based on the standard method [26]. Phenol concentrations were measured via a spectrophotometer (Shimadzu UV-2450, Japan) after chloroform extraction. The absorbance of the colored complex of phenol with 4- amino antipyrine was detected at $460 \mathrm{~nm}$ [26]. Moreover, to detect the abiotic degradation of phenol during the experiment, a blank control (BG11 medium with phenol and without algal cells) was designed to measure the concentration of phenol every two days.

\subsection{Statistical Analyses}

Statistical analyses were performed using SPSS 19.0 (IBM, Armonk, NY, USA). One-way analysis of variance (ANOVA) was applied to determine the significance of differences among the different treatments and least significant difference (LSD) multiple comparison was performed $(p<0.05$ was considered as the level of significance). Data were expressed as mean \pm standard deviation (SD). Logistic growth model was used to fit the data and describe the population dynamics of M. aeruginosa and C. pyrenoidosa.

Based on the growth curves, half-maximal effective concentration $\left(\mathrm{EC}_{50}\right)$ was estimated at $96 \mathrm{~h}$ in terms of interpolated concentration that would inhibit growth by $50 \%$ over a specific period $(96 \mathrm{~h})$. $\mathrm{EC}_{50}$ was estimated using a dose-response model for probit analysis on the fourth day [27].

Growth curves were fitted according to the following logistic function:

$$
N_{(t)}=K /\left(1+e^{a-r t}\right)
$$

where $N_{(t)}$ is the cell concentration $\left(10^{5}\right.$ cells $\left.\mathrm{mL}^{-1}\right)$ at $\mathrm{t} K$ is the carrying capacity $\left(10^{5}\right.$ cells $\left.\mathrm{mL}^{-1}\right)$ of the population, defined as maximum sustainable population biomass in a given space; $a$ is the coefficient indicating the intercept of growth curves; $r$ is the intrinsic growth rate, and $t$ is the duration of culture [14,17].

The occurrence of inflection on growth curves reflects the initiation of inhibition, which was calculated using the following formula:

$$
T_{p}=a / r
$$

where $T_{p}$ is the initiation of inhibition, $a$ is coefficient indicating the intercept of the growth curves, and $r$ is the intrinsic growth rate. 
The Lotka-Volterra competitive model [28] was used to calculate the population dynamics of the two species under the stress of organic compounds in co-cultures [14,15], which was calculated using the following formula:

$$
\begin{aligned}
& \frac{N m n-N m n-1}{t n-t n-1}=\frac{r m n N m n-1(K m n-N m n-1-\alpha N c n-1)}{K m n} \\
& \frac{N c n-N c n-1}{t n-t n-1}=\frac{r c n N c n-1(K c n-N c n-1-\beta N m n-1)}{K c n}
\end{aligned}
$$

where $N_{m n}\left(N_{m n-1}\right)$ and $N_{c n}\left(N_{c n-1}\right)$ represent the cell concentrations of $M$. aeruginosa and C. pyrenoidosa, respectively, when they were co-cultured at day $t_{n}\left(t_{n-1}\right) ; r_{m n}$ and $r_{c n}$ are the intrinsic growth rates of M. aeruginosa and C. pyrenoidosa, respectively, which are calculated according to the mono-cultures; $K_{m n}$ and $K_{c n}$ are the carrying capacity of each unit of cell concentrations of M. aeruginosa and C. pyrenoidosa respectively in mono-cultures; $\alpha$ and $\beta$ are the competition coefficients in co-cultures; $\alpha$ indicates the inhibition of $C$. pyrenoidosa on M. aeruginosa; and $\beta$ represents the inhibition of M. aeruginos $a$ on C. pyrenoidosa.

\section{Results and Discussion}

\subsection{Effects of Phenol on Algal Growth in Mono- and Co-Cultures}

In this study, data were calculated and fitted by the equation to estimate the $\mathrm{EC}_{50}$ on the fourth day, because aromatic pollutants decreased the population growth and biomass of microalgae after three days [27]. Therefore, the endpoint biomass measurement for dose-response analysis after $96 \mathrm{~h}$ exposure was more convincing. Growth rates varied with species and culture types after $96 \mathrm{~h}$ of exposure to phenol, and the $\mathrm{EC}_{50}$ of $M$. aeruginosa was $80.8 \pm 0.16 \mu \mathrm{g} \mathrm{mL}^{-1}$ in mono-cultures, which dropped to $54.7 \pm 0.25 \mu \mathrm{g} \mathrm{mL} \mathrm{m}^{-1}$ in co-cultures (Table 2). This reflected that interspecific competition increased the toxicant sensitivity of $M$. aeruginosa to phenol $[29,30]$. However, C. pyrenoidosa showed high resistance to phenol, as its $\mathrm{EC}_{50}$ was as high as $565.9 \pm 0.41 \mu \mathrm{g} \mathrm{mL}-1$ in mono-cultures. A previous work studied four nitrophenolics (o-nitrophenol, $p$-nitrophenol, $m$-nitrophenol, 2, 4-dinitrosophenol) toward the growth of C. vulgaris and two cyanobacteria (Nostoc muscorum and Nostoc linckia), and the $\mathrm{EC}_{50}$ of $C$. vulgaris was in the range of 55 to $128 \mu \mathrm{g} \mathrm{mL}^{-1}$, while the $\mathrm{EC}_{50}$ values of two cyanobacteria were 32 to $82 \mu \mathrm{g} \mathrm{mL}^{-1}$ [31]. These data were similar to our results, but the nitrophenolic compound is more toxic than phenol to Chlorella sp..

\begin{tabular}{|c|c|c|c|c|c|}
\hline \multirow{2}{*}{ Species } & \multirow{2}{*}{ Culture Type } & \multirow{2}{*}{$\mathrm{EC}_{50}\left(\mu \mathrm{g} \mathrm{mL}^{-1}\right)$} & \multicolumn{3}{|c|}{ Probit Regression Equation } \\
\hline & & & $a$ & $b$ & $r^{2}$ \\
\hline \multirow{2}{*}{ M. aeruginosa } & mono-culture & $80.8 \pm 0.16$ & 1.16 & 2.2 & 0.979 \\
\hline & co-culture & $54.7 \pm 0.25$ & 1.03 & 1.58 & 0.996 \\
\hline \multirow{2}{*}{ C. pyrenoidosa } & mono-culture & $565.9 \pm 0.41$ & 0.49 & 1.36 & 0.980 \\
\hline & co-culture & $\mathrm{NC}$ & $\mathrm{NC}$ & $\mathrm{NC}$ & $\mathrm{NC}$ \\
\hline
\end{tabular}

Table 2. $\mathrm{EC}_{50}$ of phenol for M. aeruginosa and C. pyrenoidosa in mono- and co-cultures.

$i$ : Probit regression equation is in the form of $y=a x+b$, where $y=$ probit (\% control), $x=\lg$ [phenol concentration (in $\mu \mathrm{g} \mathrm{mL}^{-1}$ )], $\mathrm{a}$ is the slope, and $\mathrm{b}$ is the $\mathrm{y}$-intercept. NC refers to no calculation because the data were not fit to the dose-response model.

As for quantitative analyses, M. aeruginosa unicells were much more accessible for enumeration than colonies. Population dynamics and interspecific competition between the two species can be analyzed accurately by flow cytometry and ecological models. It was the reason unicellular M. aeruginosa was chosen for this study.

Growth curves of M. aeruginosa and C. pyrenoidosa in mono- and co-cultures are displayed in Figure 1. In mono-cultures, the growth of M. aeruginosa was markedly inhibited by high concentration 
(200 $\mu \mathrm{g} \mathrm{mL}^{-1}$ ) of phenol in the beginning (Figure 1d), while the cell concentration of C. pyrenoidosa increased by $61 \%$ and $54 \%$ in 20 and $200 \mu \mathrm{g} \mathrm{mL}^{-1}$ treatment groups, respectively (Figure 1c,d). Growth hormesis was observed in some algae after exposure to chemicals, based on the findings of previous studies that conducted the dose-response experiments [12,32]. Hormesis is a term for the stimulatory effects caused by a low concentration of the toxic agent. Hormesis phenomenon in M. aeruginosa was also observed in this study at low concentrations of phenol, but it exhibited a dose-response effect when phenolic concentration increased, showing a significant inhibition in growth rate. However, C. pyrenoidosa grew well despite the increase in phenolic concentration. The ecotoxicity of phenol occurs from the damage to cell membranes via hydrophobic interaction with lipid bilayer structures [33], and phenol could also penetrate cells and damage inner systems, such as endoplasmic reticulum, nuclei, and their components [10]. Moreover, the reactivity of phenol with biomolecules is related to the ease with which it donates free electrons to oxidized substrates and the oxidative stress caused by free radicals and reactive oxygen species (ROS), such as superoxide radicals or hydrogen peroxide [10].

In co-cultures, the growth of $M$. aeruginosa was inhibited even at low concentration $\left(20 \mu \mathrm{g} \mathrm{mL}^{-1}\right)$ of phenol, and its $\mathrm{EC}_{50}$ is shown in Table 2. After 22 days, M. aeruginosa established dominance in 0,2 , and $20 \mu \mathrm{g} \mathrm{mL} \mathrm{m}^{-1}$ treatment groups. In contrast, cell concentrations of $C$. pyrenoidosa were significantly higher than those in the control in all but the $2 \mu \mathrm{g} \mathrm{mL} \mathrm{L}^{-1}$ treatment group. Moreover, its cell concentration in $200 \mu \mathrm{g} \mathrm{mL} \mathrm{m}^{-1}$ group was about twice that in the co-cultures without phenol. Thus, C. pyrenoidosa showed high resistance and strong competitiveness under phenolic stress (Figure 1).
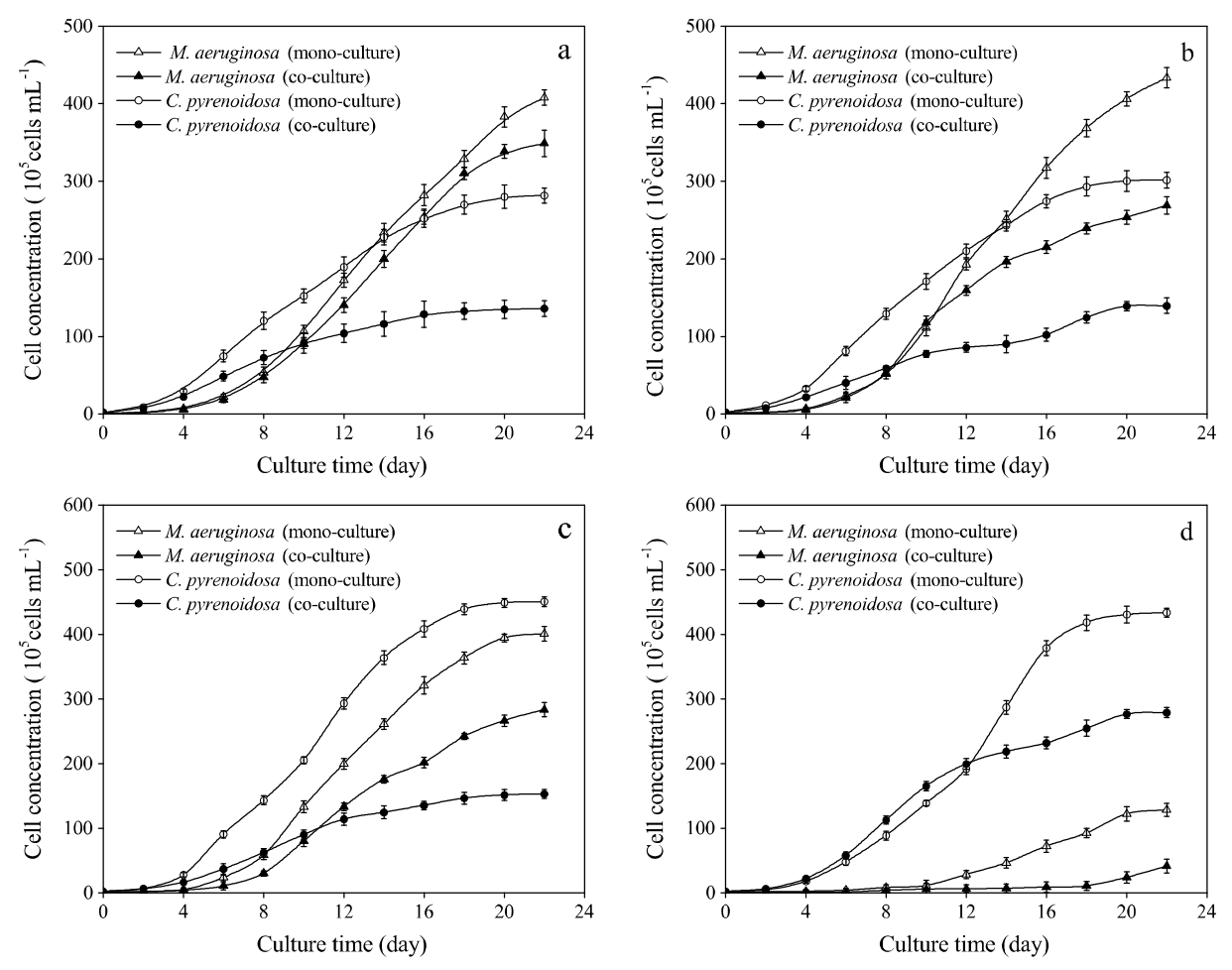

Figure 1. Growth curves of M. aeruginosa and C.pyrenoidosa in mono-cultures and co-cultures under different treatments of phenol: (a) $0 \mu \mathrm{g} \mathrm{mL}^{-1}$, (b) $2 \mu \mathrm{g} \mathrm{mL} \mathrm{m}^{-1}$, (c) $20 \mu \mathrm{g} \mathrm{mL} \mathrm{L}^{-1}$, and (d) $200 \mu \mathrm{g} \mathrm{mL} \mathrm{m}^{-1}$.

\subsection{Growth Parameters and Inflection Points}

Growth parameters of M. aeruginosa and C. pyrenoidosa in mono-cultures and co-cultures are presented in Table 3. Given that the coefficient of determination $\left(R^{2}\right)$ exceeded 0.9 for each treatment for both culture types, it implies that the logistic equation (Equation (1)) nicely fitted the growth curves in Figure 1. The carrying capacity $(K)$, intrinsic growth rate $(r)$, and initiation of inhibition $\left(T_{p}\right)$ of C. pyrenoidosa in co-cultures were lower than those in mono-cultures. For M. aeruginosa, the carrying 
capacity $(K)$ and the intrinsic growth rate $(r)$ in mono-cultures were higher than those in co-cultures of all groups (Table 3 ). However, the $T_{p}$ for $M$. aeruginosa in co-cultures appeared sooner than that in mono-cultures (Table 3).

In co-cultures, the competitive inhibition parameters $\alpha$ (C. pyrenoidosa against M. aeruginosa) and $\beta$ (M. aeruginosa against $C$. pyrenoidosa) were calculated based on the data in Table 3, according to Equations (3) and (4). Averages of the competitive inhibition parameters after the occurrence of inflection points are shown in Table 4. The value of $\beta$ was $1.75 \pm 0.07$ (while $\alpha$ was $-1.26 \pm 0.12$ ) in the co-cultures with no phenol. Interestingly, $\beta$ slightly dropped when phenol was added. Furthermore, when phenol reached $20 \mu \mathrm{g} \mathrm{mL}{ }^{-1}, \beta$ was below zero. This indicated that the interspecific competition between $M$. aeruginosa and C. pyrenoidosa had been altered by phenol. In co-cultures, M. aeruginosa established dominance in 0,2 , and $20 \mu \mathrm{g} \mathrm{mL}^{-1}$ treatment groups, but $C$. pyrenoidosa became the dominant species in the $200 \mu \mathrm{g} \mathrm{mL}^{-1}$ group. In the low-concentration groups $\left(0,2\right.$, and $\left.20 \mu \mathrm{g} \mathrm{mL}^{-1}\right)$, phenol concentration was lower than $\mathrm{EC}_{50}$ of $M$. aeruginosa $\left(80.8 \pm 0.16 \mu \mathrm{g} \mathrm{mL}{ }^{-1}\right)$ and far less than $\mathrm{EC}_{50}$ of $C$. pyrenoidosa $\left(565.9 \pm 0.41 \mu \mathrm{g} \mathrm{mL}^{-1}\right)$. Under these conditions, $M$. aeruginosa could maintain a higher growth rate and longer exponential phase compared with C. pyrenoidosa (Figure 1 and Table 3). While, in the highest group $\left(200 \mu \mathrm{g} \mathrm{mL} \mathrm{m}^{-1}\right)$, phenol inhibited the growth of M. aeruginosa markedly, but C. pyrenoidosa vigorously resisted phenolic stress. Phenol could be metabolized as an organic carbon source for C. pyrenoidosa [3]. Thus, a high concentration of phenol overturned their interspecific competition.

Table 3. Logistic equation parameters for two species in mono- and co-cultures.

\begin{tabular}{|c|c|c|c|c|c|c|c|}
\hline Species & Culture Type & $\begin{array}{l}\text { Phenol Treatment } \\
\qquad\left(\mu \mathrm{g} \mathrm{mL}^{-1}\right)\end{array}$ & $\begin{array}{c}K \\
\left(* 10^{5} \text { cells } \mathrm{mL}^{-1}\right)\end{array}$ & $a$ & $r$ & $R^{2}$ & $T_{p}$ (day) \\
\hline \multirow{8}{*}{ M. aeruginosa } & \multirow{4}{*}{ mono-culture } & 0 & 408.1 & 5.73 & 0.41 & 0.96 & 13.9 \\
\hline & & 2 & 433.6 & 5.71 & 0.41 & 0.95 & 13.9 \\
\hline & & 20 & 401.2 & 5.71 & 0.43 & 0.98 & 13.3 \\
\hline & & 200 & 128.6 & 5.78 & 0.40 & 0.98 & 14.5 \\
\hline & \multirow{4}{*}{ co-culture } & 0 & 348.8 & 5.55 & 0.37 & 0.98 & 15.0 \\
\hline & & 2 & 268.8 & 5.17 & 0.37 & 0.96 & 14.0 \\
\hline & & 20 & 283.6 & 5.52 & 0.38 & 0.98 & 14.5 \\
\hline & & 200 & 41.4 & 4.00 & 0.22 & 0.95 & 18.2 \\
\hline \multirow{8}{*}{ C. pyrenoidosa } & \multirow{4}{*}{ mono-culture } & 0 & 281.8 & 4.25 & 0.43 & 0.96 & 9.8 \\
\hline & & 2 & 301.6 & 4.44 & 0.45 & 0.98 & 9.9 \\
\hline & & 20 & 450.6 & 4.98 & 0.49 & 0.98 & 10.2 \\
\hline & & 200 & 433.6 & 5.36 & 0.48 & 0.97 & 11.2 \\
\hline & \multirow{4}{*}{ co-culture } & 0 & 133.4 & 3.22 & 0.41 & 0.95 & 7.9 \\
\hline & & 2 & 139.6 & 3.25 & 0.36 & 0.98 & 9.0 \\
\hline & & 20 & 153.2 & 3.61 & 0.37 & 0.97 & 9.8 \\
\hline & & 200 & 279.1 & 4.28 & 0.39 & 0.92 & 11.0 \\
\hline
\end{tabular}

Note: $R^{2}$ is the determinant coefficient of regression, $K$ is the carrying capacity, $a$ is a constant, and $r$ is the intrinsic growth rate.

Table 4. Competitive coefficients of M. aeruginosa and C. pyrenoidosa in co-cultures.

\begin{tabular}{ccc}
\hline Phenol Treatment $\left(\mu \mathrm{g} \mathrm{mL}^{-\mathbf{1}}\right)$ & $\boldsymbol{\alpha}$ & $\boldsymbol{\beta}$ \\
\hline 0 & $-1.26 \pm 0.12$ & $1.75 \pm 0.07$ \\
2 & $-0.84 \pm 0.08^{\mathrm{n}}$ & $1.58 \pm 0.22$ \\
20 & $-0.94 \pm 0.18^{\mathrm{n}}$ & $-0.60 \pm 0.05$ \\
200 & $-1.12 \pm 0.26$ & $-2.19 \pm 0.32$ \\
\hline
\end{tabular}

Note: $\alpha$ is the competitive parameter of $C$. pyrenoidosa against M. aeruginosa, while $\beta$ is that of $M$. aeruginosa against C. pyrenoidosa; $\mathrm{n}$ means there is no significant difference between the treatment and the control. 


\subsection{Photosynthetic Activities of Two Algae in Mono-Cultures}

To further investigate the different responses of two algae to phenol, photosynthetic activities were analyzed in mono-cultures. Algal $\mathrm{Chl} a$ fluorescence is one of the sensitive, non-invasive, and efficient methods to detect cellular responses to pollutants. Analyses on Chl $a$ fluorescence induction curves contributed to the evaluation on photosynthetic electron transport chain, which provides valuable information between the inflow and outflow of energy flux in PSII [34-36]. In this study, Chl $a$ fluorescence was measured in mono-cultures on the fourth day. JIP-test parameters of M. aeruginosa (Figure 2a) showed considerable changes compared to the parameters of C. pyrenoidosa (Figure 2b).
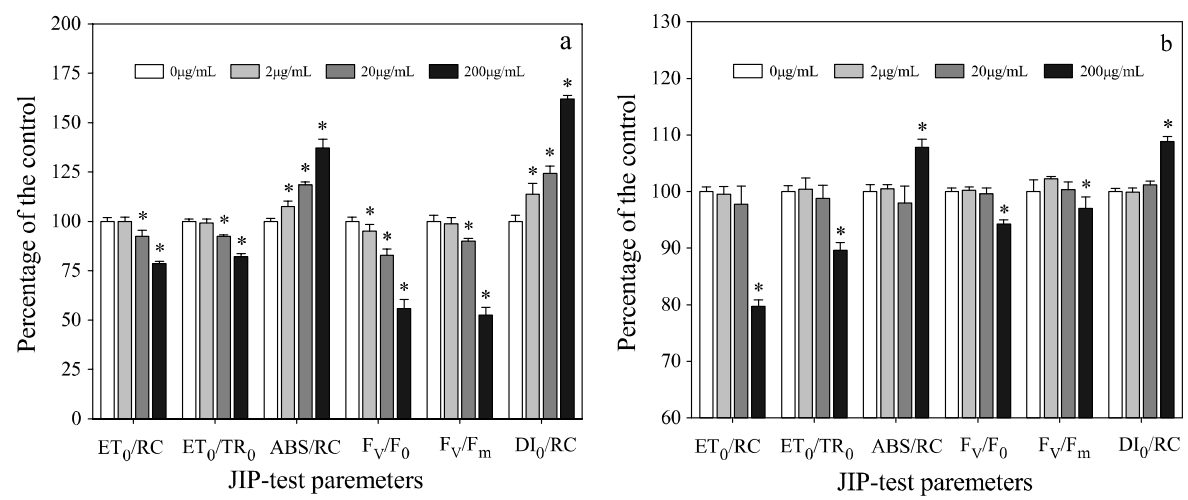

Figure 2. Changes in JIP-test parameters (compared to the control of the same species, and displayed as the percentage of the control) at different concentrations of phenol: (a) M. aeruginosa and (b) C. pyrenoidosa. The significant difference compared to the control is indicated as $*(p<0.05)$.

$F_{v} / F_{m}$ is a useful parameter to indicate the maximal photochemical efficiency of PSII in algal cells after dark adaptation, which is related to the probability that an absorbed photon would be trapped by the reaction center $(R C)$, resulting in the reduction of primary plastoquinone $\left(Q_{A}\right)$ pool [23]. Values of $F_{v} / F_{m}$ in $M$. aeruginosa cells were significantly reduced $(p<0.05)$ in 20 and $200 \mu \mathrm{g} \mathrm{mL}$ treatment groups, with the $200 \mu \mathrm{g} \mathrm{mL} \mathrm{L}^{-1}$ group showing a decreasing of more than $50 \%$. However, for C. pyrenoidosa, $F_{v} / F_{m}$ value decreased slightly in the $200 \mu \mathrm{g} \mathrm{mL}^{-1}$ group only (Figure 2).

Under normal conditions, reactive oxygen species (ROS) are produced at a lower rate. However, some pollutants lead to a dramatic increase in ROS production, which reduces the number of active reaction centers or causes the light-harvesting complexes (LHCs) to detach from the core of PSII [24,37]. For $M$. aeruginosa, $A B S / R C$, a measurement of the average absorption per active $\mathrm{RC}$ or the average amount of absorbing chlorophylls per active RC [23], significantly increased at $200 \mu \mathrm{g} \mathrm{mL}^{-1}$ phenol. It has been suggested that the inactivation of RC can account for the increase of $A B S / R C$ [38]. Moreover, we found that the sharpest decrease of $F_{v} / F_{0}(44 \%)$ resulted from the reduction in the ratio of active and inactive reaction centers of PSII (Figure 2a). This might have occurred due to the transformation, which turned some of the active $R C$ to 'silent $\mathrm{RC}^{\prime}$ ( $R \mathrm{C}^{\mathrm{si}}$ ). The $\mathrm{RC}{ }^{\text {si }}$ have two characteristics: (a) these centers can neither reduce $Q_{A}$ nor back transfer their excitation energy to the antenna. Hence the corresponding PSII units do not contribute to the variable fluorescence, and their fluorescence yield constantly remains at low levels and is equal to those of units with open RC; and (b) they are re-activated as soon as the stress that provoked the conformational modification ceases [34]. The percentage of treated algae's $\mathrm{RC}^{\mathrm{si}}$ compared to the control group was calculated using the following equation [23].

$$
R C^{s i}=\left[1-\frac{(A B S / R C)^{c}}{(A B S / R C)}\right] \times 100 \%=\left\{1-\frac{\left(M_{0} / V_{j}\right)^{c}}{\left(M_{0} / V_{j}\right)} \times \frac{\left[1-\left(F_{0} / F_{m}\right)\right]}{\left[1-\left(F_{0} / F_{m}\right)\right]^{c}}\right\} \times 100 \%
$$

where $R C$ is the reaction center ( $R C$ in the control is signed with a superscript ' $c$ ', inactive or silent $R C$ is shown with a superscript ' $s i$ '). Other terms in the equation are listed in Table 1. 
For M. aeruginosa, the percentage of RC ${ }^{\text {si }}$ increased with the concentration of phenol, and there were significant differences between the treatments and the control $(p<0.05$; Figure 3$)$. Therefore, the reduction of active $\mathrm{RC}$ contributed to the decrease of $F_{v} / F_{0}$ ratio. Meanwhile, the increased $\mathrm{RC}^{\mathrm{si}}$ could explain the significant augmentation of $A B S / R C$ and $D I_{0} / R C$, as it increased by $37 \%$ and $62 \%$ in the $200 \mu \mathrm{g} \mathrm{mL}^{-1}$ group, respectively (Figure 2a). However, the percentage of $\mathrm{RC}^{\mathrm{si}}$ in C. pyrenoidosa cells only increased by $13.2 \%$ in $200 \mu \mathrm{g} \mathrm{mL}^{-1}$ group (Figure 3). Similarly, the electron transport from $\mathrm{Q}_{\mathrm{A}}$ to $\mathrm{Q}_{\mathrm{B}}$ flux per $\mathrm{RC}\left(E T_{0} / \mathrm{RC}\right)$ and the electron transport probability $\left(E T_{0} / \mathrm{TR}_{0}\right)$ decreased under the stress of phenol [38]. As to M. aeruginosa, the $E T_{0} / R C$ and $E T_{0} / \mathrm{TR}_{0}$ decreased significantly in 20 and $200 \mu \mathrm{g} \mathrm{mL} \mathrm{m}^{-1}$ groups (Figure 2a). For C. pyrenoidosa, there was a significant difference $(p<0.05)$ between the $200 \mu \mathrm{g} \mathrm{mL}^{-1}$ treatment and the control group, as for the $200 \mu \mathrm{g} \mathrm{mL}-1$ group, $E T_{0} / \mathrm{RC}$ and $E T_{0} / T R_{0}$ decreased by $20 \%$ and $10 \%$, respectively (Figure $2 \mathrm{~b}$ ).

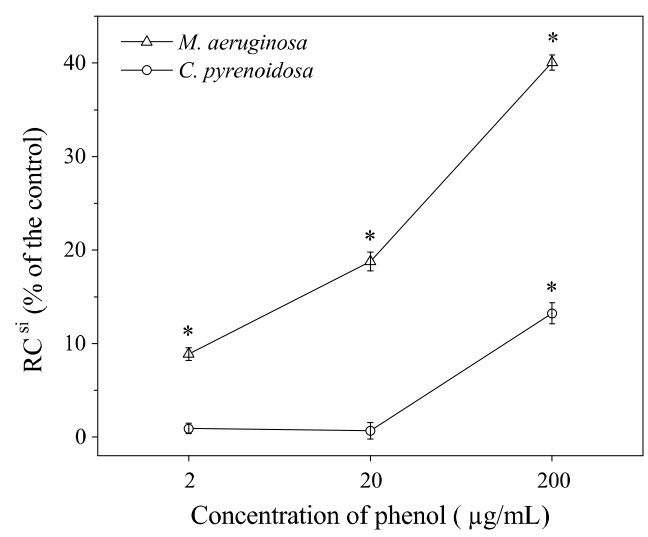

Figure 3. Percentage of the silent reaction center $\left(\mathrm{RC}^{\mathrm{si}}\right)$ at different concentrations of phenol in mono-cultures Significant difference compared with the control is indicated as * $(p<0.05)$.

To determine the inhibiting site in the electron transport chain, the fraction of oxygen-evolving complex (OEC) of the treated samples was calculated, and results showed that fraction of OEC remained unchanged in all treated groups. This suggests that electron transport on the donor side of PSII was not affected by phenol. In addition, the decrease of the parameter $\mathrm{F}_{\mathrm{v}} / \mathrm{F}_{0}$ also indicates an alteration in the acceptor side of the PSII complex [39]. Therefore, the acceptor side of PSII in electron transport action was inhibited by phenol, which was similar to the detrimental effects of polycyclic aromatic hydrocarbon on wheat [24]. Furthermore, the decrease of $E T_{0} / \mathrm{RC}$ indicated an inhibition on $\mathrm{Q}_{\mathrm{A}}{ }^{-}$, which was similar to artemisinine (act as a kind of algicide to control Microcystis), an inhibitor of the electron flow beyond $\mathrm{Q}_{\mathrm{A}}{ }^{-}[40,41]$. The effects of phenol on PSII were comparable to those of aromatic herbicides (ioxynil). Ioxynil can interact with different amino acid residues on the D1 protein of PSII in cyanobacterium (Synechocystis salina), and inhibit the electron transport from $\mathrm{Q}_{\mathrm{A}}{ }^{-}$to $\mathrm{Q}_{\mathrm{B}}$ [39].

Moreover, cyanobacterial cells exhibit an internal thylakoid system organized as a series of roughly parallel double-membrane layers distributed within the cytoplasm, whereas green algae have chloroplasts, which contain an inner membrane system formed by bands of stacked thylakoids (grana) and thylakoids running singly in the stroma [39]. It has also been confirmed that there are differences in the polypeptides composition of OEC and peripheral light-harvesting antenna of PSII between cyanobacteria and green algae [42]. These differences can influence photosynthetic activity and toxicant sensitivity to phenolic contamination.

During the experiment, the abiotic degradation or volatilization of phenol was very slow in the blank control during the experiment (Table S1). However, in treatment groups, the measured values were significantly lower than designed values $(p<0.01)$, which was due to the cellular adsorption or digestion by physiological metabolism [3]. Especially in C. pyrenoidosa mono-cultures and co-cultures, the dissolved phenol concentrations were markedly lower than those in M. aeruginosa mono-cultures $(p<0.05)$. A previous study found that phenol could be metabolized as an organic carbon source 
for C. pyrenoidosa [3]. Further studies will focus on the distribution and digestion of phenol in C. pyrenoidosa cells.

\section{Conclusions}

In this study, M. aeruginosa established dominance in co-cultures with C. pyrenoidosa when phenol was below or equal to $20 \mu \mathrm{g} \mathrm{mL} \mathrm{m}^{-1}$. However, C. pyrenoidosa was the dominant species at $200 \mu \mathrm{g} \mathrm{mL}$ of phenol. This means that phenolic pollution could overturn the competition between M. aeruginosa and C. pyrenoidosa. M. aeruginosa was more sensitive to phenol because its photosynthetic activity was inhibited in the acceptor side of electron transport chain and the number of active reaction centers reduced significantly.

Supplementary Materials: The following are available online at http://www.mdpi.com/1660-4601/16/20/3947/s1, Table S1: Changes of the dissolved phenol concentration $\left(\mu \mathrm{g} \mathrm{mL}^{-1}\right)$.

Author Contributions: Conceptualization, X.T.; methodology, K.D.; software, K.D.; validation, Z.D.; formal analysis, K.D.; investigation, Z.D.; resources, X.T.; data curation, Y.H.; writing-original draft preparation, K.D.; writing - review and editing, K.P. and X.H.; funding acquisition, X.T.

Funding: This study was supported by the National Natural Science Foundation of China (31470507), the Fundamental Research Funds for the Central Universities (2019B14014), the National Water Pollution Control and Treatment Science and Technology Major Project (2017ZX07603), the Project Funded by the Priority Academic Program Development of Jiangsu Higher Education Institutions (PAPD), and the Top-notch Academic Programs Project of Jiangsu Higher Education Institutions (TAPP).

Conflicts of Interest: The authors declare no conflict of interest.

\section{References}

1. Newsted, J.L. Effect of light, temperature, and $\mathrm{pH}$ on the accumulation of phenol by Selenastrum capricornutum, a green alga. Ecotoxicol. Environ. Saf. 2004, 59, 237-243. [CrossRef] [PubMed]

2. Ramakrishnan, B.; Megharaj, M.; Venkateswarlu, K.; Naidu, R.; Sethunathan, N. The impacts of environmental pollutants on microalgae and cyanobacteria. Crit. Rev. Environ. Sci. Technol. 2010, 40, 699-821. [CrossRef]

3. Das, B.; Mandal, T.K.; Patra, S. A comprehensive study on Chlorella pyrenoidosa for phenol degradation and its potential applicability as biodiesel feedstock and animal feed. Appl. Biochem. Biotechnol. 2015, 176, 1382-1401. [CrossRef] [PubMed]

4. Mukherjee, D.; Bhattacharya, S.; Kumar, V.; Moitra, J. Biological significance of $\left[{ }^{14} \mathrm{C}\right]$ phenol accumulation in different organs of a murrel, Channa punctatus, and the common carp, Cyprinus carpio. Biomed. Environ. Sci. 1990, 3, 337-342.

5. Aleksieva, Z.; Ivanova, D.; Godjevargova, T.; Atanasov, B. Degradation of some phenol derivatives by Trichosporon cutaneum, R57. Process Biochem. 2002, 37, 1215-1219. [CrossRef]

6. Chen, H.; Zhu, L.; Yang, K.; Ge, F.; Chen, Y. Concentration and pollution characteristics of phenolic compounds in Qiantang River. China Environ. Sci. 2005, 25, 729-732.

7. Song, H.; Wang, D.; Xu, X.; Wang, H.; Chen, X.; Luo, Q.; Wang, Z.; Du, Y. Occurrence of 14 phenols in 24 typical drinking water sources of China. Acta Sci. Circumstantiae 2014, 34, 355-362.

8. Ying, P.J.; Tang, Y.; Hu, L.J. A survey on an accident of phenolic pollution. Mod. Prev. Med. 2006, 33, 594-595.

9. Scragg, A.H. The effect of phenol on the growth of Chlorella vulgaris, and Chlorella VT-1. Enzym. Microb. Technol. 2006, 39, 796-799. [CrossRef]

10. Kottuparambil, S.; Kim, Y.J.; Choi, H.; Kim, M.S.; Park, A.; Park, J.; Shin, W.; Han, T. A rapid phenol toxicity test based on photosynthesis and movement of the freshwater flagellate, Euglena agilis Carter. Aquat. Toxicol. 2014, 155, 9-14. [CrossRef]

11. Matorin, D.N.; Plekhanov, S.E.; Bratkovskaia, L.B.; Yakovleva, O.V.; Alekseev, A.A. The effect of phenols on the parameters of chlorophyll fluorescence and reaction of P700 in the green algae Scenedesmus quadricauda. Biophysics 2014, 59, 374-379. [CrossRef]

12. Chen, C.P.; Zhang, T.T.; He, M.; Wu, A.P.; Nie, L.W. Effects of aniline and phenol on freshwater algae growth. Chin. J. Appl. Ecol. 2007, 18, 219-223. 
13. Dziga, D.; Suda, M.; Bialczyk, J.; Czaj-Prokop, U.; Lechowski, Z. The alteration of Microcystis aeruginosa biomass and dissolved microcystin-LR concentration following exposure to plant-producing phenols. Environ. Toxicol. 2007, 22, 341-346. [CrossRef] [PubMed]

14. Jin, X.; Jiang, J.; Sheng, L.; Jin, M. Interspecies competition between Microcystis aeruginosa and Scenedesmus obliquus under phenanthrene stress. Pol. J. Environ. Stud. 2014, 23, 1609-1616.

15. Zhu, W.; Chen, H.M.; Guo, L.L.; Li, M. Effects of linear alkylbenzene sulfonate (LAS) on the interspecific competition between Microcystis and Scenedesmus. Environ. Sci. Pollut. Res. 2016, 23, 16194-16200. [CrossRef]

16. De Morais, P.; Stoichev, T.; Basto, M.C.P.; Ramos, V.; Vasconcelos, V.M.; Vasconcelos, M.T.S.D. Pentachlorophenol toxicity to a mixture of Microcystis aeruginosa and Chlorella vulgaris cultures. Aquat. Toxicol. 2014, 150, 159-164. [CrossRef]

17. Bi, R.; Wang, Y.; Wang, R.; Li, W.; Tang, X. Effect of anthracene on the interaction between Platymonas helgolandica var. tsingtaoensis and Heterosigma akashiwo in laboratory cultures. J. Ocean Univ. China 2015, 14, 105-113. [CrossRef]

18. Yang, J.; Tang, H.; Zhang, X.; Zhu, X.; Huang, Y.; Yang, Z. High temperature and pH favor Microcystis aeruginosa to outcompete Scenedesmus obliquus. Environ. Sci. Pollut. Res. 2018, 25, 4794-4802. [CrossRef]

19. De Morais, P.; Stoichev, T.; Basto, M.C.P.; Ramos, V.; Vasconcelos, V.M.; Vasconcelos, M.T.S.D. Cyanobacterium Microcystis aeruginosa response to pentachlorophenol and comparison with that of the microalga Chlorella vulgaris. Water Res. 2014, 52, 63-72. [CrossRef]

20. Kong, Q.X.; Zhu, L.Z.; Shen, X.Y. The toxicity of naphthalene to marine Chlorella vulgaris under different nutrient conditions. J. Hazard. Mater. 2010, 178, 282-286. [CrossRef]

21. Stanier, R.; Kunisawa, R.; Mandel, M.; Cohen-Bazire, G. Purification and properties of unicellular blue-green algae (Order Chroococcales). Bacteriol. Rev. 1971, 35, 171-205. [PubMed]

22. Reynolds, C.S. The Ecology of Phytoplankton; Cambridge University Press: Cambridge, UK, 2006; pp. 1-37.

23. Duan, Z.P.; Tan, X.; Li, N.G. Ultrasonic selectivity on depressing photosynthesis of cyanobacteria and green algae probed by chlorophyll-a fluorescence transient. Water Sci. Technol. 2017, 76, 2085-2094. [CrossRef] [PubMed]

24. Tomar, R.S.; Jajoo, A. A Quick investigation of the detrimental effects of environmental pollutant polycyclic aromatic hydrocarbon fluoranthene on the photosynthetic efficiency of wheat (Triticum aestivum). Ecotoxicology 2013, 22, 1313-1318. [CrossRef] [PubMed]

25. Sun, D.; He, N.; Chen, Q.; Duan, S. Effects of lanthanum on the photosystem II energy fluxes and antioxidant system of Chlorella Vulgaris and Phaeodactylum Tricornutum. Int. J. Environ. Res. Public Health 2019, 16, 2242-2253. [CrossRef] [PubMed]

26. Koh, S.M.; Dixon, J.B. Preparation and application of organo-minerals as sorbents of phenol, benzene and toluene. Appl. Clay Sci. 2001, 18, 111-122. [CrossRef]

27. Othman, H.; Leboulanger, C.; Le Floc'h, E.; Mabrouk, H.H.; Hlaili, A.S. Toxicity of benz (a) anthracene and fluoranthene to marine phytoplankton in culture: Does cell size really matter? J. Hazard. Mater. 2012, 243, 204-211. [CrossRef] [PubMed]

28. Perron, M.C.; Qiu, B.; Boucher, N.; Bellemare, F.; Juneau, P. Use of chlorophyll a fluorescence to detect the effect of microcystins on photosynthesis and photosystem II energy fluxes of green algae. Toxicon 2012, 59, 567-577. [CrossRef]

29. Foit, K.; Kaske, O.; Liess, M. Competition increases toxicant sensitivity and delays the recovery of two interacting populations. Aquat. Toxicol. 2012, 106-107, 25-31. [CrossRef]

30. Knillmann, S.; Stampfli, N.C.; Beketov, M.A.; Liess, M. Intraspecific competition increases toxicant effects in outdoor pond microcosms. Ecotoxicology 2012, 21, 1857-1866. [CrossRef]

31. Madhavi, D.R.; Umamaheswari, A.; Venkateswarlu, K. Effective concentrations of nitrophenolics toward growth yield of selected microalgae and cyanobacteria isolated from soil. Ecotoxicol. Environ. Saf. 1995, 32, 205-208. [CrossRef]

32. Stebbing, A.R.D. Hormesis-The stimulation of growth by low levels of inhibitors. Sci. Total Environ. 1982, 22, 213-234. [CrossRef]

33. Michałowicz, J.; Duda, W. Phenols-sources and toxicity. Pol. J. Environ. Stud. 2007, 16, 347-362.

34. Strasser, R.J.; Srivastava, A.; Tsimilli-Michael, M. The fluorescence transient as a tool to characterize and screen photosynthetic samples. In Probing Photosynthesis: Mechanism, Regulation \& Adaptation; Yunus, M., Pathre, U., Mohanty, P., Eds.; CRC Press: Boca Raton, FL, USA, 2000; pp. 445-483. 
35. Gao, Q.T.; Tam, N.F.Y. Growth, photosynthesis and antioxidant responses of two microalgal species, Chlorella vulgaris and Selenastrum capricornutum, to nonylphenol stress. Chemosphere 2011, 82, 346-354. [CrossRef] [PubMed]

36. Kalaji, H.M.; Jajoo, A.; Oukarroum, A.; Brestic, M.; Zivcak, M.; Samborska, I.A.; Cetner, M.D.; Łukasik, I.; Goltsev, V.; Ladle, R.J. Chlorophyll a fluorescence as a tool to monitor physiological status of plants under abiotic stress conditions: A review. Acta Physiol. Plant. 2016, 38, 102. [CrossRef]

37. Kummerová, M.; Vanova, L. Chlorophyll fluorescence as an indicator of fluoranthene phototoxicity. Plant Soil Environ. 2007, 53, 430-436. [CrossRef]

38. Volterra, V. Fluctuation in the abundance of a species considered mathmatically. Nature 1926, 118, 558-560. [CrossRef]

39. Yotsova, E.K.; Stefanov, M.A.; Dobrikova, A.G.; Apostolova, E.L. Different sensitivities of photosystem II in green algae and cyanobacteria to phenylurea and phenol-type herbicides: Effect on electron donor side. $Z$. Nat. C 2017, 72, 315-324. [CrossRef]

40. Tsimilli-Michael, M.; Stamatakis, K.; Papageorgiou, G.C. Dark-to-light transition in Synechococcus sp. PCC 7942 cells studied by fluorescence kinetics assesses plastoquinone redox poise in the dark and photosystem II fluorescence component and dynamics during state 2 to state 1 transition. Photosynth. Res. 2009, 99, 243-255. [CrossRef]

41. Ni, L.; Acharya, K.; Hao, X.; Li, S.; Li, Y.; Li, Y. Effects of artemisinin on photosystem II performance of Microcystis aeruginosa by in vivo chlorophyll fluorescence. Bull. Environ. Contam. Toxicol. 2012, 89, 1165-1169. [CrossRef]

42. Barber, J. Crystal structure of the oxygen-evolving complex of photosystem II. Inorg. Chem. 2008, 47, 1700-1710. [CrossRef]

(C) 2019 by the authors. Licensee MDPI, Basel, Switzerland. This article is an open access article distributed under the terms and conditions of the Creative Commons Attribution (CC BY) license (http://creativecommons.org/licenses/by/4.0/). 